\title{
A refundação do trabalho no fluxo tensionado ${ }^{1}$
}

\author{
Jean Pierre Durand \\ tradução de Leonardo Gomes Mello e Silva
}

Q ue as empresas tenham reatado com os lucros desde há uma década parece não haver dúvida. As razões para isso são múltiplas, mas há pelo menos uma que permanece incontestável, a saber, a alta dos ganhos de produtividade. Pode-se então interrogar sobre quais são os fundamentos, as fontes desses novos ganhos de produtividade obtidos há dez ou quinze anos.

A primeira resposta que vem à mente é a resposta tecnológica: as tecnologias de informação e de comunicação (doravante designadas simplesmente TIC - e não N ovas Tecnologias de Informação, uma vez que elas começam a não ser mais tão novas!) permitiram, tanto na fábrica como nos escritórios, melhorar não apenas a produtividade aparente do trabalho, mas também a produtividade global, em particular em razão da queda rápida dos custos, possibilitada pela potência de cálculo da microeletrônica.

De fato, se as TIC têm um papel nesses ganhos de produtividade, elas não são, de nosso ponto de vista, o seu fundamento principal. Com efeito, na indústria - e para ficar somente nesse exemplo - o robô pode substituir vários operários não-qualificados, porém ele nunca o substitui tanto quanto se diz, pois o robô exige uma presença humana importante em seu entorno: controle, conservação e mão-de-obra de manutenção para as empilhadeiras etc. No terciário, a burótica, o microcomputador e a informática em geral têm aumentado consideravelmente a eficácia dos colarinhos-brancos, da secretária ao engenheiro, passando pelo executivo. $M$ as, ao mesmo tempo,
1. A expressão flux tendu está associada ao termo just-in-time, mas tem um significado para além dele. Enquanto just-intime significa organizar 0 fluxo contínuo de matériase de informações dentro da empresa e entre em- presas, fluxo tensionado é um paradigma que organiza a disciplina (e o modo) do trabalho por meio do fluxo contínuo de todasasatividades(incluindo o trabalho intelectual). Por exemplo: a relação cliente-fornecedor, aplicada hoje em todas as situações, é uma ilustração da implementação geral do paradigma do fluxo tensionado (N. do T.). 
2. Sobre a nossa definição do modelo produtivo e sobre o seu interesse heurístico como orga nizador do vai-e-vem científico (integrando ao mesmo tempo os aportes teóricos e os dados extraídos do campo) entre os níveis micro e ma cro - sem criar um pseudonível meso, como, por exemplo, o objeto "empresa" -, ver Durand (1999a). as demandas vindas das direções em termos de volume de informação e de precisão dessa informação têm na prática absorvido os ganhos de produtividade do trabalho de escritório - o acompanhamento em tempo real das performances exige o tratamento de uma quantidade sempre maior de informação mais e mais precisa. Enfim, a complexificação da produção e sobretudo das trocas reclama o tratamento de quantidades cada vez maiores de informação. Dizendo de outro modo, se asTIC participam diretamente dos ganhos de produtividade, elas o fazem apenas de modo parcial, de modo que não poderiam explicar a amplidão desses ganhos que se observam desde pouco mais de uma década.

Por outro lado, as TIC participam indiretamente dos ganhos de produtividade ao fornecer a base de uma nova etapa de racionalização do trabalho: pode-se notar isso por meio da Gestão da Produção A ssistida por Computa dor, na qual a informática permite uma gestão mais estreita dos materiais e dos homens. De forma análoga, as trocas cada vez mais automatizadas de dados vão conduzir a um controle crescente da atividade de produção de bens e serviços e a novos ganhos de produtividade no futuro.

N o entanto, atualmente, não são as TIC que fundamentam o essencial dos ganhos de produtividade. Esses últimos provêm de reorganizações da produção e do trabalho, e daquilo que Ihe é correspondente, a saber, um novo regime de mobilização da mão-de-obra. 0 presente artigo toma por objeto a nova combinatória produtiva nascida no curso das últimas décadas (Figura 1), a qual aproxima o aparelho produtivo (portanto, as tecnologias), com sua organização da produção e do trabalho, do regime de mobilização dos trabalhadores. Tal combinatória produtiva é ela mesma um elemento ou uma subparte do modelo produtivo pós-fordista de acumulação do capital2 $^{2}$. Essa nova combinatória produtiva aparece aqui como um objeto particular, microssociológico (e microeconômico!) de um conjunto mais vasto que é o modelo produtivo tomado globalmente.

Pode-se representar a nova combinatória produtiva por meio de três pólos: a integração reticular (organização geral da produção de bens e serviços), a generalização do fluxo tensionado (com suas conseqüências sobre a organização do trabalho) e o modelo da competência como novo regime de mobilização da mão-de-obra. AsTIC intervêm transversalmente nesses três pólos, pois, de uma certa maneira, as reorganizações e as inovações atuais não poderiam ocorrer sem elas (por exemplo, o grau alcançado pela organização em fluxo tensionado jamais poderia chegar no ponto em que se encontra com uma gestão apenas do tipo papel e lápis, uma vez que o fluxo tensionado reclama freqüentemente o tratamento e a comunicação instantâneos da informação). 
Ainda que ela não seja 0 objeto deste artigo, a integração reticular pode, por sua vez, ser desagregada em três componentes principais, que mantêm laços estreitos com os dois outros pólos citados:

- Integração pesquisa/ industrialização, cujo objetivo é, para cada empresa, a comercialização o mais rapidamente posśvel de um produto ou de um serviço saídos de descobertas científicas (ou outras). Com efeito, 0 preço do "bilhete de entrada" em um mercado é em geral tão menos elevado quanto mais cedo se entra nele, sendo que há uma vantagem econômica quando se é o criador de um nicho ou de um mercado. Daí a necessidade, para as firmas, de manter uma vigilância informacional que seja ao mesmo tempo científica, tecnológica, estratégica, comercial, entre outras, e de integrar o mais rápido possível os dados então disponíveis à sua oferta comercial.

- Integração funcional significa integração na empresa e na unidade de produção: trata-se de descompartimentar os serviços e as funções por meio de uma reorganização (integração organizacional) e pela circulação - e em seguida utilização sem entraves - dos dados informáticos (integração pelos dados). 0 exemplo pedagógico dessa integração funcional é a engenharia simultânea, que reza que o escritório de projetos (concepção), o de métodos (industrialização) e, por fim, a fábrica (a fabricação) trabalhem conjuntamente e sobretudo de maneira simultânea, a fim de reduzir os tempos de desenvolvimento de um produto, de melhorar a sua qualidade e de abaixar os seus custos de fabricação (adquirindo melhor "manufaturabilidade"); esses deveriam ser os frutos de uma cooperação estreita entre serviços - mantida pela troca intensiva de informações extraídas das bases de dados comuns e utilizadas pelas máquinas - e os programas que automatizam, por sua vez, uma parte não negligenciável do trabalho intelectual.

- Integração na firma-rede é uma outra maneira de designar a externalização das atividades das empresas na direção de subcontratantes e de fornecedores, freqüentemente chamados "parceiros". Se ontem 0 cliente requisitava a um fornecedor um produto simples (elemento de um todo complexo que o cliente montava por sua própria conta), hoje o que ele demanda a um fornecedor de primeira linha é conceber e fabricar um conjunto complexo, feito a partir de componentes oriundos de subcontratantes de escalões inferiores. 0 mesmo é válido para uma série de serviços a empresas, ramo que se desenvolve com grande velocidade. A empresa reticular aparenta-se, assim, a um conjunto de satélites cada vez mais complexo, caracterizado por intensiva troca de 
informações. A interdependência dos atores, ou a integração na firmarede, deve por sua vez ser cruzada com a integração funcional, já mencionada, em cada empresa, a fim de entender a natureza das transformações organizacionais empreendidas há duas décadas. Como se verá, essas últimas participam em grande medida do reforço das pressões do tempo exercidas sobre os empregados em situações de trabalho transformadas, em que a concorrência, de resto bem real, serve também de pretexto para reduzir as porosidades no tempo de trabalho.

Tal integração reticular conecta-se com os outros pólos de nosso esquema, uma vez que o fluxo tensionado e 0 modelo da competência combinam-se para criar novas eficácias tanto do trabalho como, de maneira mais global, dos investimentos realizados.

FIGURA 1

$\mathrm{N}$ ova $\mathrm{C}$ ombinatória P rodutiva

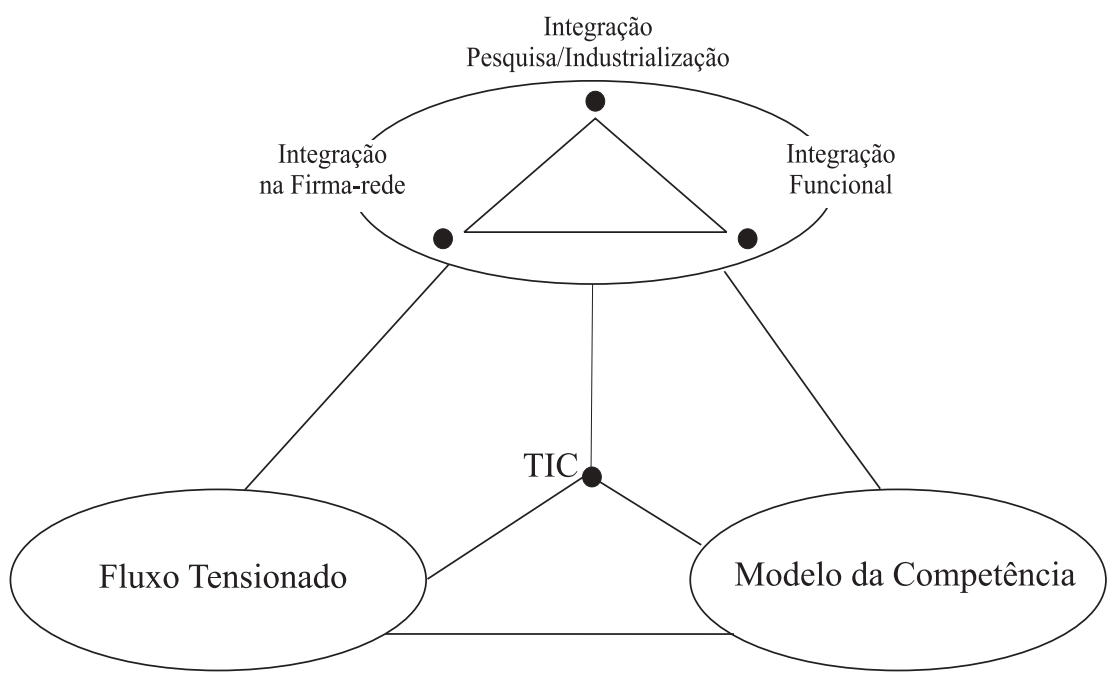

A revolução do fluxo tensionado

As virtudes do fluxo desde Ford são bem conhecidas - virtudes do ponto de vista do empregador: a velocidade da passagem da esteira transportadora condiciona o ritmo de trabalho dos homens (à força de trabaIho com volume constante, é claro). Dizendo de outro modo, as cadências de trabalho dos homens não dependem de uma norma (por exemplo, 0 número de peças por dia) para ser aplicada por homens a outros homens. aqui é uma máquina que dita o ritmo de intervenção dos homens.

0 fluxo tensionado é bem mais exigente do que o fluxo fordiano já que, além do ritmo de trabalho dos operários que a ele estão atados, mobiliza os 
trabalhadores indiretos (vigilância mas também controle) encarregados de sua continuidade: a tensão do fluxo requer a atenção e a mobilização de todos os empregados da fábrica. Sem pretender listar todas as aplicações do fluxo tensionado, pode-se assim mesmo tomar consciência de sua generalização como modo de organização da produção e do trabalho. A indústria recorre cada vez mais ao just-in-time; as cadeias de fast-food, do congelador ao consumidor, construíram um fluxo tensionado, pois os hambúrgueres são cozidos de acordo com a demanda (um hambúrguer não deve esperar mais do que onze minutos sob pena de ser destruído); nas redes de supermercados, todo consumo é registrado a fim de disparar um pedido a partir de um certo limiar para o fornecedor, que o disponibiliza imediatamente: a cadeia de informação, de um lado, e o fluxo-matéria, de outro, não devem nunca ser rompidos. 0 s circuitos monetários (o tempo de processamento de um cheque, por exemplo); os hubs ou plataformas concentrando no tempo as correspondências entre aviões nos aeroportos; as correspondências do correio, por exemplo, são tantos outros casos concretos de colocação em operação do princípio do fluxo tensionado.

Para compreender a revolução conceitual empreendida, é necessário voltar-se rapidamente sobre a gênese do fluxo tensionado e, assim fazendo, relembrar o princípio do fluxo na produção fordiana ${ }^{3}$ (Figura 2). N esse caso, quer se trate de fabricação de peças ou de tratamento de documentos individuais, cada posto de trabalho produz extraindo de um estoque a montante e em seguida constituindo um estoque a jusante; em geral, procede-se por "rajadas" ou por "campanhas", o que significa que se produz a mesma coisa durante várias horas ou vários dias, custando muito cara a mudança de produção. Sabendo-se que tudo o que é produzido será vendido, um estoque comercial alimenta o mercado final. Esse sistema faz da planificação uma atividade determinante, que organiza o fluxo ativador da produção.

O fluxo tensionado nasceu com a pilotagem pelo fim, isto é, a idéia de que só se deveria fabricar aquilo que o mercado já tenha pedido. Tal conceito generalizado a toda a cadeia de produção significa que cada posto de trabalho é cliente daquele logo acima, o qual, na incerteza do que Ihe será demandado, não constitui mais estoques como no fluxo fordiano. Basta estar em condições de entregar à jusante, no momento certo (just-in-time) e segundo a quantidade demandada, os produtos ou serviços necessários. H istoricamente, na Toyota - que é o inventor desse sistema -, cada posto de trabal ho era prevenido por um ticket (um kanban) do pedido à jusante. Donde um duplo fluxo: matéria, de cima para baixo da cadeia (com uma ausência ou uma quase ausência de estoque comer-
3. É necessário precisar aqui que a produção fordiana de produtos individuais, ainda que se refira ao mesmo conceito de "fordista", difere do fluxo fordiano associado ao transportador ou à esteira, descrito anteriormente. Aqui o conceito descreve uma produção em massa de cuja venda se tem certeza, e com relação à qual nem o custo, nem a qualidade têm importância: pode-se então constituir estoques, mesmo com osinconvenientes que acarretam. 
cial), e informacional, de baixo para cima. É preciso assinalar que de todo modo há um fluxo informacional descendente, qual seja, o da planificação das matérias primas e das disponibilidades dos meios para tornar a produção possível. Isso, contudo, não elimina o fato de que é o fluxo informacional "puxado" que determina a produção.

FIGURA 2

F luxoA tivador eF luxoTensionado

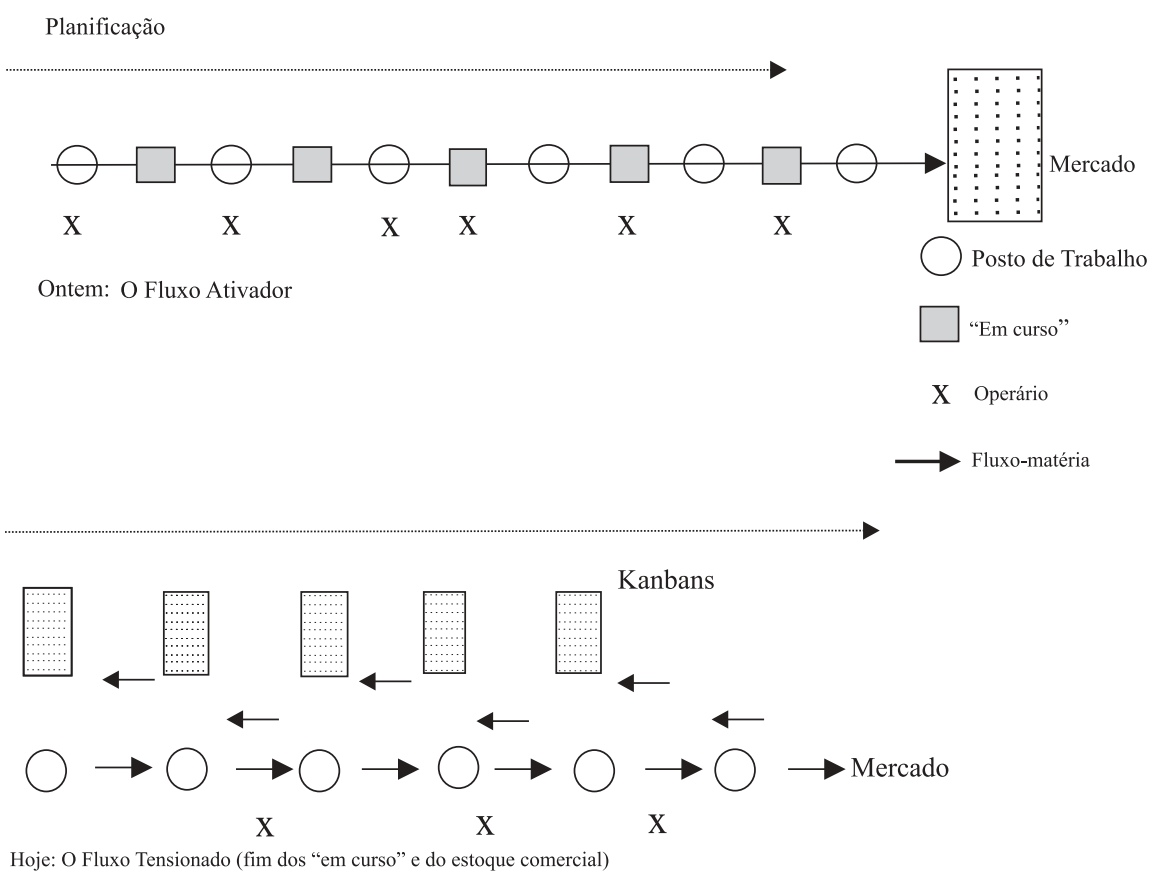

Do ponto de vista econômico, as vantagens da ausência de estoques ou de "em curso" são as seguintes:

- Fim da imobilização de capital nos "em curso".

- R eatividade total e imediata às evoluções da demanda.

- Identificação imediata da não-qualidade conduzindo a "remédios" rápidos (anteriormente, estoques inteiros podiam ser colocados de lado).

- R elevância dos gargalos de estrangulamento e dos disfuncionamentos, antes escondidos pela existência de estoques e "em curso".

N 0 entanto, tais vantagens não negligenciáveis são secundárias em relação às vantagens organizacionais e políticas do fluxo tensionado. Com efeito, não romper o fluxo tensionado tem conseqüências consideráveis do ponto de vista da organização do trabalho, das mudanças culturais e das 
pressões sobre os empregados. M anter tensionado o fluxo significa ao mes mo tempo:

- Suprimir as panes. Donde a mobilização do Total Productive M aintenance $(\text { TPM })^{4}$, o qual visa a criar uma manutenção preventiva. Trata-se de uma mudança cultural entre os operários de manutenção, os quais não serão mais avaliados segundo sua destreza e rapidez em reparar uma instalação (o que é visível, fácil de mensurar e algumas vezes espetacular), mas segundo sua capacidade de impedir ou prevenir as panes (o que é, para o reparador, do domínio do inviśvel). Para preparar uma tal revolução das mentalidades, o método do "cinco $S$ " é freqüentemente considerado um verdadeiro adestramento social dos empregados, com respeito aos quais se exige uma transformação radical de comportamento.

- Entregar apenas bens de qualidade (caso contrário, os postos de trabaIho não podem mais funcionar) significa suprimir todas as causas de não-qualidade nos procedimentos de fabricação. Daí a ativação de procedimentos de qualidade total que visam à responsabilização de todo empregado por meio do autocontrole da qualidade do trabalho efetuado em cada posto.

- Mudar rapidamente de "campanha" de produção já que as séries são menores (não há mais estoques-tampão). Aqui também novos métodos são implementados, os quais com bastante freqüência suprimem o recurso aos responsáveis pelas regulagens e aos instrumentadores: são os próprios operários de fabricação que procedem às mudanças de ferramentas e às diversas regulagens.

- Melhorar permanentemente o sistema de produção, tanto do ponto de vista técnico quanto organizacional. Esse kaiz en ${ }^{5}$ ("bonificação" em japonês) visa à supressão dos acasos na produção e das paradas de máquinas, mas principalmente à redução permanente dos custos, em particular dos custos de mão-de-obra: a competição primeiramente nacional naToyota e, depois, a globalização levam "naturalmente" as direções de empresa a exigir ganhos permanentes de produtividade que podem atingir 20\% ao ano, dependendo da firma.

Além de suas funções puramente técnicas - não romper o fluxo tensionado -, tais instrumentos sociotécnicos têm um papel fundamental na aceitação social da nova combinatória produtiva. Com efeito, eles são os meios de fazer partilhar concretamente com os empregados subalternos os objetivos da empresa: quem pode ser contra a qualidade? Q uem pode
4. Em português: M anutenção ProdutivaTotal MPT (N. doT.).

5. 0 kaizen refere-se a uma atitude, assim como também a um método, de melhoramento incremental contínuo por parte dos envolvidos na produção (operários e pessoal técnico) (N .doT.). 
se levantar contra a reatividade imediata ao mercado? Q uem pode ser contra a redução de custos (e, pois, do incremento da produtividade) para manter a empresa viva? Esses são os objetivos econômicos da empresa que são transmitidos por meio de conteúdos témicos quando de reuniões de círculos de qualidade, de círculos de progresso, de grupos de progresso, entre outras. São objetivos gerais (e exigências de acionistas) traduzidos em microobjetivos locais adaptados ao campo de preocupações dos empregados, fechados em um espaço social e técnico restritos. Proclamar os objetivos sem relação com a vida cotidiana no trabalho não tem grande efeito; porém, construir práticas imediatas diretamente ligadas a uma representação, torna-a palpável: "não há ideologia sem prática", dizia Althusser. $N$ esse caso, a TPM , o kaizen e a qualidade total constituem práticas que correspondem à globalização e às suas exigências competitivas, e até mesmo às exigências dos acionistas. E mais: todas essas práticas que transformam as relações entre empregados subalternos e agentes técnicos, técnicos ou engenheiros, e entre os primeiros e a direção, dão vida à famosa "gestão participativa", dessa vez carregada de um conteúdo real: as relações estreitas que se estabelecem entre todas essas categorias sociais permitem contornar o representante do pessoal ou a seção sindical, e até mesmo torná-los supérfluos e inúteis.

Ao mesmo tempo, esses microobjetivos locais podem construir novos espaços de autonomia dos empregados ou, ao menos, fazer crer que esses novos espaços existem. Para ir direto ao ponto, poder-se-ia mostrar que são mudanças mais de forma do que de fundo, ou seja, que tais técnicas socioprodutivas modificam mais o discurso sobre o trabalho do que os conteúdos do trabalho: se transformações existem no trabalho de vigilância de processos (mas não era no trabalho indireto que já residia uma maior autonomia dos assalariados?), elas são bem mais raras do que no trabalho direto. Em geral, o que mudou foi tanto a percepção do trabalho - cuja realidade não deve ser ocultada e cujo impacto social não deve ser subestimado - como seus conteúdos, onde subsistem uma parte não negligenciável de procedimentos, os quais aliás podem ser reforçados com o desenvolvimento de procedimentos tipo ISO 9000. É possível também mostrar que a prescrição do trabalho incide cada vez menos sobre as tarefas, sendo impelida, por assim dizer, "para cima", sobre os objetivos e os meios de atingi-los (cf. Durand, 2000a): nem por isso deixa de ser uma prescrição, em que a autonomia de execução permanece estreitamente enquadrada pelos imperativos gerenciais.

0 fato de essas técnicas socioprodutivas incrementarem um pouco a autonomia dos empregados, ou transformarem antes a representação do 
trabalho do que o trabalho em si mesmo, faz com que as novas condições de produção fundadas no fluxo tensionado sejam mais bem aceitas, embora freqüentemente acompanhadas do reforço do ritmo de trabalho por meio da redução da porosidade do tempo trabalhado. Trazer o fluxo tensionado para o centro da análise justifica-se pela sua generalização. A lém dos exemplos já citados - cadeias de fast-food, redes de supermercados, circuitos monetários -, há outros ainda mais comprobatórios, que chegam a utilizar os clientes para tensionar o fluxo e aumentar a pressão sobre os empregados. $\mathrm{N}$ os supermercados, o número de caixas registradoras é calculado para que a todo o momento da jornada, da semana e do ano, uma fila de três a cinco pessoas mantenha 0 ritmo de trabalho das atendentes de caixa (ritmo esse que é incessantemente acrescido pelo melhoramento das técnicas produtivas: leitor de código de barras, scanner de código de barras, esteira rolante etc.). N os clubes de férias, o bufê é uma das maiores invenções produtivistas nos serviços, equivalendo certamente à transportadora de Ford: os clientes organizam a pressão sobre eles mesmos, apressando-se em consumir as entradas e o prato principal a fim de estarem seguros de que sua sobremesa preferida não acabará... Por isso, às vezes eles jantam em menos de meiahora, tornando possível que quatrocentos convidados façam sua refeição em apenas cem lugares, enquanto o pessoal de serviço e de cozinha deve estar sob pressão dos quatro serviços realizados em uma duração que dificilmente ultrapassa a duas horas. Isso sem contar que, mais e mais, apenas as horas efetivamente trabalhadas são pagas.

$\mathrm{N}$ a indústria, a reorganização das fábricas em "ilhas de produção" põe fim ao circuito anárquico de peças que podiam habitar meses inteiros entre duas máquinas antes de serem usinadas: em lugar de ter seções homogêneas de máquinas-ferramenta, entre as quais circulavam lentamente as peças (em uma fábrica do subúrbio de Boston, havia, por exemplo, peças tão empoeiradas que obrigaram o escritório de métodos a reconhecer que nem sabia de sua existência), as peças são hoje reunidas em famílias e usinadas nas linhas (ou ilhas de produção) de máquinas-ferramenta dedicadas a uma ou várias famílias: as peças passam de máquina em máquina sem estoques intermediários, em fluxo tensionado, com um prazo estrito a ser respeitado pela equipe de operários. Ainda na indústria, a engenharia simultânea que integra as funções de concepção e de industrialização faz com que os engenheiros dos escritórios de estudo devam transmitir permanentemente as informações à jusante, ao escritório de métodos, para que este prepare os futuros meios de produção: caso um dos atores se atrase ou cesse de desenhar, ele penaliza imediatamente 0 outro; em outras palavras, não há outra escolha senão produzir segundo o ritmo 
6. Aqui se esconde um jogo de palavras com os termos "polícia" (flic) e "fluxo" (flux): "le flic est dans le flux" (N . do T.).

\section{A fim de não cair em} um "franglês" de toda forma inaceitável, achamos por bem utilizar 0 termo "grupo de trabaIho", mantendo a diferença conceitual com a situação da Europa do N orte nos anos de 1970.

Aqui nos distinguimos claramente de um certo número de autores- ede gerentes - que deslocaram o conteúdo conceitual do teamwork no sentido do "trabalho em grupo", confundindo, algumas vezes de forma voluntária, os dois, a fim de mascarar as diferenças de natureza e com isso aceitar mais facilmente os constrangimentos do primeiro. Para maiores detalhes sobre o fundamento dessas distinções, ver "I Introdução" em D urand et al. (1998). coletivo.

D e forma geral, a famosa relação cliente-fornecedor aparece, sem nunca tê-lo declarado, como uma conceituação do fluxo tensionado: não apenas aplica-se simultaneamente aos serviços (do qual ela é originária) e à indústria, mas também reúne a totalidade das características do fluxo tensionado, qual seja, entregar just-in-time a quantidade demandada de bens ou de serviços, da qualidade requisitada, sempre a preço mais baixo.

Se nos fixamos agora na análise dos efeitos do fluxo tensionado sobre o trabalho, sua primeira conseqüência é de mobilizar todos os empregados: pode-se falar de "naturalização dos constrangimentos", já que as prescrições, os procedimentos, as pressões do tempo, as urgências - tudo com um efetivo humano mínimo - do sistema produtivo não são mais mediatizados por um homem - o chefe -, mas inscritos na necessidade de manter a tensão do fluxo produtivo. O s constrangimentos parecem, assim, exteriores ao mundo social ou econômico, eles passam a ser inscritos em um fluxo material neutro - como toda matéria parece ao homem, isto é, exterior a ele mesmo. Tal exterioridade confere-Ihes suas características "naturais", isto é, são independentes da vontade dos homens e, portanto, tornam-se constrangimentos necessários de se respeitar. De fato, ou bem se aceita o fluxo tensionado e os constrangimentos a ele associados, ou bem se abandona a empresa. A interiorização dessa aceitação naturalizada difere de modo notável da relação social que o empregado podia manter anteriormente com a direção, pois agora a "polícia está no fluxo" 6 e a direção, ela mesma, é subjugada pelo fluxo, reduzida a tarefas administrativas (antes que de comando) cujo objetivo essencial é de manter tensionado o fluxo.

Isso é um empreendimento coletivo: a organização do trabalho é, pois, coletiva, diferentemente das situações fordianas, onde cada empregado era atado a um posto fixo, em alguns casos a uma máquina. Agora, fala-se em trabalho em grupo, trabalho em equipe, e dever-se-ia inventar um terceiro conceito para traduzir teamwork. Pois "trabalho em grupo" se refere à organização em grupos semi-autônomos oriunda da Escandinávia e "trabalho em equipe" está fortemente associado ao fordismo. O ra, a organização atual, assentada no teamconcept, difere desses dois tipos organizacionais:

- Fim dos postos de trabalho pessoais significa que o domínio do fluxo passa pelo recorte do fluxo de produção de bens ou de serviços em segmentos produtivos. A cada segmento é alocado um grupo de trabaIho (a team).

- Cada grupo de trabalho ${ }^{7}$ é responsável coletivamente pela qualidade e 
quantidade produzida (a quantidade, em geral, não se avalia mais por volume produzido, mas em uma ratio de disponibilidade de instalações).

- O s empregados são mais e mais polivalentes, isto é, podem e devem intervir em qualquer lugar do segmento cujo grupo tem responsabilida de, e, se houver necessidade, os melhores de cada grupo podem até mesmo intervir em outros segmentos. U ma tal polivalência significa também a publicidade - no sentido de tornar público - e a socialização de saberes, sobretudo dos savoir-faire que cada um adquire no curso de sua experiência pessoal. Ela é, aliás, coerente com os instrumentos sociotécnicos apresentados (TPM, qualidade total, kaiz en etc.), já que estes são o suporte e o lugar tanto da publicidade como da socialização dos savoirfaire. A polivalência dos empregados acarreta, ainda, sua intercambialidade: com efeito, a disponibilização dos savoir-faire de cada um para todos (e, por conseqüência, a apropriação deles pelas direções de empresa por meio de sua objetivação em procedimentos mais e mais finos) enfraquece a posição individual: a fortíssima mobilidade interna (até mesmo extrema) ilustra o fato do aumento da substutibilidade dos empregados em geral.

- A organização e a responsabilidade coletivas no grupo de trabalho aumentam as pressões dos pares sobre cada indivíduo: atrasos, ausências repetidas, cansaço ou fracas performances não são mais dependentes ou invocadas pelo chefe, mas pelo grupo, que pode ver suas performances reduzidas ou a parte de trabalho de cada um aumentar, caso um dos elementos não respeite a norma média estabelecida no grupo e por ele. Ser colocado de lado pelo grupo, estresse e assédio no trabalho têm origem, muito freqüentemente, na organização do trabalho em grupo e não na pressão de um responsável sobre o indivíduo. 0 bserva-se aqui um efeito direto dessa "naturalização" dos constrangimentos que leva a descartar o mais fraco, uma vez que aqueles são, por definição, incontornáveis.

- Criação do teamleader, denominado freqüentemente monitor, chefe de grupo - um par, um semelhante, em ascensão social - e que, por uma pequena diferença salarial e sem poder hierárquico delegado, aceita ocupar uma função contraditória, qual seja, a de controlar seus colegas, fazendo passar os objetivos da direção da empresa e, ao mesmo tempo, manter-se como um empregado preso às tarefas e ao constrangimento do fluxo. Além disso, suas chances de promoção são tanto mais reduzidas quanto 0 encolhimento dos degraus hierárquicos (do qual ele participa ao aceitar ser monitor, sem pertencer a qualquer degrau hierár- 
quico) e a limitação, na mesma proporção, dos meios que the são oferecidos.

Em resumo, a organização do trabalho em grupo (teamwork) é perfeitamente coerente ao fluxo tensionado, ou seja, os postos de trabalho independentes nunca poderiam assegurar a tensão do fluxo, na medida em que ela repousa sobre a interdependência das eventuais causas de sua ruptura; somente a cooperação estreita entre empregados, isto é, o trabalho coletivo, permite manter o fluxo tensionado ao preço de uma mão-de-obra reduzida. Pois mesmo se aqui a questão do custo de produção é pouco desenvolvida, é preciso ter em mente que ela permanece sendo uma prioridade das direções de empresa, e que seria impossivel separar a questão do fluxo tensionado da questão de redução dos custos - essa é, aliás, a principal lição de Taichi 0 hno (1989), que organiza o just-in-time na Toyota para reduzir os custos (e não apenas para fazer desaparecer os "em curso" imobilizando capital), a fim de que apareçam claramente a uns e a outros os desperdícios de todos os tipos que as grandes séries produzem, assim como os estoques que as acompanham. A liás, o Toyota Production System, fundado sobre o kaizen, as sugestões e mais ainda sobre 0 trabalho permanente dos agentes técnicos de melhorias da produtividade (cf. Shimizu, 1999), visa primeiramente à redução de custos da mão-de-obra que, no sistema japonês, era então destinada quer a outras tarefas, quer a outras fábricas. Pensar a tensão do fluxo sem redução dos custos de mão-de-obra não tem sentido: os dois objetivos são indissociáveis e se reforçam mutuamente. Com certeza, o fluxo seria ainda mais tensionado - isto é, todas as causas de disfuncionamento teriam desaparecido - se cada grupo de trabalho dispusesse de recursos humanos em quantidade e qualidade suficientes para atingir seus objetivos. $M$ as a natureza mesma do sistema social de produção, o capitalismo, impede tal otimização, já que o tratamento da questão dos custos - busca do lucro máximo - o leva a reduzir especialmente os custos de mão-de-obra. Como enfrentar essa contradição entre tensão do fluxo e redução dos custos de mão-de-obra? Contornando-a por meio da invenção de uma outra coerência entre organização do trabaIho em grupo (teamwork) e responsabilização-mobilização dos empregados. É nessa responsabilização, que implica mobilização da subjetividade dos empregados, que se situa hoje o coração do modelo da competência, tal como ele é posto em funcionamento por toda parte no mundo. 


\section{0 modelo da competência}

No modelo fordiano, o empregado era remunerado segundo o posto ocupado, o qual, por sua vez, era medido de acordo com métodos ditos científicos pelos agentes técnicos. Por meio da correspondência estabelecida entre peso do posto e classificação do empregado, admitia-se implicitamente que todos os empregados ocupavam da mesma maneira o mes mo posto: aliás, a direção devia fazer respeitar esse princípio, e os "maus" elementos eram afastados seja do posto, seja da empresa. 0 aumento dos assalariados era coletivo, bastante ligado à política do Estado, que fixava anualmente o crescimento do salário mínimo, e às convenções coletivas, que decidiam os aumentos anuais por ramos. A penas os modos de progressão, e sobretudo de promoção, eram individualizados.

Em duas décadas, sob as pressões das direções de empresa e das associações patronais, o sistema de remuneração resvalou na direção de uma individualização do salário. C ada vez mais é a pessoa que é remunerada, e sobretudo a maneira pela qual ela conserva o posto ou a função que the é confiada. Dito de forma mais abrupta, as direções tendem a remunerar mais e mais o grau de mobilização dos empregados tomados individualmente. Esse grau assume o nome de comportamento ou de competência. Com efeito, se a qualificação - anteriormente critério de habilitação para ocupar um posto e assim para receber uma classificação - repousava sobre os saberes (em geral adquiridos na escola ou em centros de formação) e os savoirfaire (destrezas e "manhas" adquiridas na prática), ou seja, sobre a experiência, a competência, por seu turno, acrescenta o famoso "saber ser" (savoir-être). M al definido, esse último integra as atitudes do empregado diante de sua hierarquia, de seus colegas, assim como sua disponibilidade temporal (horas extras...) e intelectual e, de maneira mais geral, seu comportamento em face das exigências ligadas ao trabalho.

A definição da competência pelo M edef (Mouvement des Entrepreneurs D émocratiques Français) ${ }^{8}$ é, desse ponto de vista, edificante:

8. 0 M edef é uma associação patronal (N. doT.).

[...] a competência profisssional é uma combinação de conhecimentos, savoir-faire, experiências e comportamentos, exercendo-se em um contexto preciso. Ela é constatada quando de sua colocação em marcha em situação profissional, a partir da qual elaévalidada. É, pois, à empresa que compete assinalá-la, avaliáala, validála e fazê-la evoluir.

Para além da consideração explícita do comportamento, que, como afirma Philippe Zarifian, tornou-se uma "competência social", essa definição afir- 
9. Digamo-lo novamente: tal desequilíbrio caracteriza a situação geral, mas para os segmentos do mercado de trabalho nos quais a empresaé submetidaàs pressões salariais dos ofertantes de força de trabalho, a situação é a mesma característica das convenções coletivas no fordismo (cf. o primeiro capítulo sobre a apresentação das grandes transformações socioeconômicas na Suécia em Durand (1994).

10. Pode-se consultar um quadro classificatório do tipo descrito aqui em Durand (2001, pp. 222-223) (N. do T.). ma que somente a empresa pode validar a competência: adeus, pois, à indexação do salário ao diploma emitido pelo M inistério da Educação ou qualquer centro de formação. A competência só pode ser avaliada e validada em situação profissional. Por isso, adeus também ao reconhecimento da qualificação levado de uma empresa a outra: o empregado não pode mais fazer reconhecer a sua qualificação alhures, apenas na situação profissional específica em que ela é avaliada, salvo se, é claro, o mercado de trabalho, em um segmento, contrariar essa lógica. Contudo, geralmente o reconhecimento da competência deve ser reinicializado a cada mudança de empresa. Dito de outro modo, essa definição da competência introduz um profundo desequilíbrio em relação às negociações coletivas de antanho, já que põe em jogo, de um lado, a potência da empresa que edita, ela só, as regras do jogo e os critérios de avaliação das competências e dos comportamentos, e, de outro, o indivíduo isolado?.

Todos os quadros de avaliação coligidos no Japão, na França e nos Estados U nidos testemunham o advento da avaliação direta dos comportamentos individuais. São em geral compostos de duas grandes partes com volume igual: a primeira, tratando dos saberes e dos savoir-faire (ou seja, a qualificação) a partir da avaliação dos resultados objetivos do trabalho; a segunda, incidindo unicamente sobre as atitudes e os comportamentos. C ertos itens podem ser particularmente sutis no quadro do teamwork, como o utilizado em uma grande firma japonesa de motos: " cooperação e colaboração com os outros e não fixação em seus próprios interesses". Trata-se de avaliar individualmente a capacidade de trabalhar em grupo. Porém, outros itens são muito mais discutíveis, tais como os que avaliam o "domínio de si e do próprio afeto" ou a "submissão ao superior". N a França, em um subcontratado do ramo automobilístico, um quadro de avaliação do pessoal de produção incide sobre os resultados efetivos do trabalho: produção, qualidade, segurança, ordem e limpeza, e polivalência. Por outro lado, no item "disponibilidade", opõe-se o operário muito bom, que "propõe ele mesmo os serviços que devem ser feitos, antes que al guém lhe peça", àquele que "recusa sistematicamente os serviços demandados" : trata- se aqui essencialmente das horas extras noturnas e também do sábado, que afastam, por exemplo, o empregado que já tenha casa própria. 0 item "sociabilidade" considera que o elemento muito bom "não faz observação negativa do superior e faz prova de uma correção perfeita diante de todos e com grande gentileza", enquanto o operário medíocre tem uma "atitude irascível diante de seus superiores, seus colegas e o pessoal de serviço" ${ }^{10}$.

Esse tipo de avaliação de comportamentos funda o modelo da competência na prescrição não mais baseada sobre as tarefas em si mesmas, mas 
nos objetivos a atingir, sem que, contudo, os meios (em particular os humanos) para alcançá-los sejam sempre fornecidos. Assim, o modelo da competência não mais controla o trabalho, mas a lealdade dos empregados, para se assegurar de que eles dirigirão suas capacidades e mobilizarão sua subjetividade no sentido de atingir os objetivos, que são raramente negociáveis, tanto em termos de conteúdo, como de meios. Eis aí também o motivo de somente a empresa poder avaliar as competências!

Avaliando a lealdade, o modelo da competência mede a conformidade à norma social (reconhece-se aqui uma certa influência japonesa) construída pelo grupo de trabalho e, em seguida, exigida pelo próprio grupo e pela direção, para manter tensionado o fluxo. Dessa forma, a avaliação individual das aptidões para o trabalho coletivo e a avaliação do engajamento individual do empregado entram em perfeita consonância com o teamwork, ele mesmo coerente com o fluxo tensionado: cada indivíduo deve ser adaptável, móvel geografica e intelectualmente, aceitando a mudança, ou seja, de uma certa maneira, ser dependente da empresa.

Isso não quer dizer que o modelo da competência significa necessariamente o inferno ou o sofrimento no trabalho, o que é sempre possível dentro de certas condições ${ }^{11}$ : o que constatamos principalmente é um des locamento das possibilidades de resistência, até mesmo de lutas sindicais, que sempre terminam por autorizar espaços de autonomia, e de jogos sociais, que tornam aceitáveis as condições de trabalho, mesmo as mais difíceis (cf. Durand e H atzfeld, 2002). N o entanto, é necessário que expliquemos o que leva os indivíduos a adotar comportamentos conforme as expectativas das direções de empresa, isto é, comportamentos leais. N o Japão, o desejo de permanecer na grande empresa, a qual remunera muito melhor os empregados (com salário direto e, sobretudo, com diversas vantagens sociais), é a origem dessa lealdade, o que nos conduziu a elaborar o conceito de implicação constrangida (cf. Durand e Durand-Sebag, 1996; Boyer e D urand, 1998): paradoxal, esse conceito diz o quanto os empregados não têm escoIha, devendo engajar-se nos objetivos empresariais para permanecer na grande empresa. Em outros lugares, e na Europa em particular, a precariedade e o temor do desemprego servem de equivalente funcional e levam os empregados a adotar o comportamento desejado - da leal dade sem falha caso queiram conservar ou aceder a um emprego. 0 modelo núcleo/ periferia, que caracteriza não somente a firma estendida com seus subcontratados, mas também todos os serviços da grande empresa, opõe um núcleo de empregaods permanentes altamente qualificados e muito bem remunerados a uma periferia de empregados precários, com qualificações não reconhecidas e com rendas diretas, e indiretas, bem inferiores.
11. Sobre nossa crítica da tese extrema do sofrimento ontológico, notadamente no trabalho, ver D urand (2000b). 
12. O bserva-se aqui todo o jogo sutil entre flexibilidade interna e externa que não pode ser compreendido sem aproblemática da busca de mobilidade pelos empregadosno sentido detirar a melhor vantagem de uma estrutura que Ihes domina.
O modelo da competência pode ser utilizado para ameaçar os empregados do núcleo com uma eventual recaída na periferia: recruta-se apenas as pessoas certas e conserva-se apenas os fiéis, a quem se promete aumento salarial e promoção, em troca de comportamentos esperados. À periferia, que serve entre outras coisas para a adaptação imediata das variações de volume oriundas da demanda, compete o papel de enquadramento social dos jovens à lealdade e à fidelidade, condições de passagem do estatuto precário à segurança (relativa) do emprego. 0 modelo núcleo/ periferia é um instrumento de integração social e/ou de aceitação das condições postas aos empregados. Por exemplo: cada um aceita uma nova carga de trabalho, isto é, certa intensificação do trabalho (por meio da redução da porosidade do tempo de trabalho) em troca de uma esperança de mobilidade, ascensional ou geográfica (abandonar a cadeia de montagem, as chamadas telefônicas nos centros de atendimento, por exemplo) para os empregados do núcleo duro; ou então uma "titularização", para aqueles da periferia ${ }^{12}$. Em outras palavras, o modelo núcleo/periferia, como estrutura diferenciada de emprego, contribui para a implementação do modelo da competência e da implicação constrangida, os quais são coerentes com o trabalho em grupo e com o fluxo tensionado.

Assim, o modelo da combinatória produtiva, tal como nós o tínhamos definido anteriormente, é totalmente coeso. Ele não deixa (ou deixa pouco) lugar à contestação e à resistência, uma vez que a avaliação individual repousa essencialmente sobre a lealdade. $\mathrm{N}$ ão apenas reprime essas manifestações, como também desenvolve práticas de integração social por meio da gerência participativa e de técnicas socioprodutivas associadas ao fluxo tensionado. Q ue lugar resta então ao sindicalismo?

\section{Sindicalismo, fluxo tensionado e trabalho em grupo}

O sindicalismo, na maior parte das situações, dispensou-se de analisar a nova combinatória emergente e perpetua práticas oriundas de períodos superados. Alguns centros de pesquisa norte-americanos estreitamente ligados ao sindicalismo efetuaram estudos a esse respeito, mas as análises irrigaram muito pouco as seções sindicais, tanto nos Estados U nidos como na Europa. E os sindicatos não se mobilizam sobre essas questões, o que constitui também um índice dos "atrasos" na percepção das mudanças estratégicas.

Como, então, sair do que se considera hoje uma crise sindical, com o declínio do número de sindicalizados ou a redução dos movimentos sociais? 0 diagnóstico dessa crise não deve conduzir à denúncia do pecado 
burocrático, diagnóstico fácil de autoflagelação, que silencia, por exemplo, sobre a melhoria considerável do nível de vida dos assalariados no 0 cidente. A tualmente, os assalariados não fazem mais da reivindicação salarial a prioridade que podiam lhe consagrar os seus pais. 0 corre que tal diagnóstico não quer ver as profundas mudanças do modelo produtivo considerado em todas as suas dimensões macro e microssociais (globalização, financerização, fluxo tensionado etc.), que indicam ao sindicalismo a passagem de um papel "curativo" para um papel de "antecipação". 0 ra, isso constitui uma verdadeira revolução cultural para esses quadros, assim como para os trabalhadores em geral, e cria problemas sérios: como mobilizar-se em torno de reivindicações fundadas sobre o virtual, sobre a antecipação em relação aos efeitos que terão as decisões e as estratégias dos grupos industriais e/ ou financeiros? O s quadros sindicais estão acostumados a se mobilizar em torno de ameaças e perigos visíveis porque imediatos, o que faz com que, geralmente, haja um atraso de percepção e que, por exemplo, as decisões de fechar uma dada unidade já tenham sido tomadas e sejam irreversíveis, ou, na melhor das hipóteses, possam ser apenas retardadas. H oje, para jogar em igualdade de condições com grupos de estrategistas mundiais, os quadros sindicais devem tanto criar estruturas, elas também mundiais, como fazer frente aos estrategistas do capital na prática, com possibilidades de mobilização mundializada e antecipadora por parte dos trabalhadores. Tudo isso mantendo-se, é claro, à escuta dos problemas cotidianos, a fim de resolvê-los.

Talvez a única solução a esse dilema e aos constrangimentos impostos pelo próprio capital seja uma verdadeira profissionalização dos sindicalistas $^{13}$. Essa expressão é ambígua e pode levar a erros de interpretação. N o entanto, não tendo sido encontrado outro termo mais apropriado, mantêmo-lo provisoriamente. É desnecessário dizer que não se trata de propor o desenvolvimento de uma burocracia pesada, composta de efetivos desligados dos membros dos sindicatos e dos trabalhadores de forma geral. Pelo contrário, profissionalizar os quadros sindicais significa:

- Dirigir-se a uma gestão das obras sociais e das instituições culturais pelos sindicalistas de tal forma que ela seja pelo menos tão eficaz como a do setor mercantil tradicional. É de se espantar que praticamente todas as instituições de turismo popular tenham fechado na França, mesmo beneficiando-se de subvenções importantes dos Comitês de Empresa $^{14}$. Hoje, a maioria deles satisfaz-se com a atribuição de descontos feitos aos empregados sobre a compra de viagens ou de temporadas vendidas em forma de kit nas grandes operadoras de turismo. 0 corre 0
13. Para um detalhamento do diagnóstico da "crise sindical" e das proposições relativas à profissionalização dos quadros sindicais, ver Durand (1999b).

14. O s C omitês de Empresa na França são instituições de representação dos empregados de uma empresa, eleitospor todos os efetivos e não apenas os sindicalizados (N. do T.). 
mesmo em todos os setores sociais e culturais geridos pelos Comitês de Empresa.

- Criticar as estratégias financeiras, produtos e procedimentos globalizados dos grupos e das empresas, avançando com proposições alternativas a fim de manter ou desenvolver o emprego onde se encontram atualmente as fábricas ou as sedes sociais, aumentando o valor adicionado das mencionadas firmas.

- Criticar, quando necessário, as escolhas feitas em matéria de tecnologias (em particular, as TIC) e de organização da produção e do trabalho, propondo alternativas compatíveis com as proposições feitas acerca das estratégias gerais.

- Criar uma força de comunicação direcionada aos membros dos sindicatos e dos trabalhadores em geral que seja, ao menos, tão eficaz quanto à dos diretores de R ecursos Humanos e dos serviços especializados, a fim de mobilizar os trabalhadores para realizar as proposições alternativas, mencionadas acima.

Em outras palavras, o objetivo é de construir entre os trabalhadores, e para eles, um nível de profissionalização igual ao das direções de empresa, no sentido de discutir com elas e reconquistar, ao mesmo tempo, a confiança dos trabalhadores e a iniciativa quanto à conduta das empresas, para que elas não satisfaçam apenas os desejos dos acionistas, mas também as necessidades dos empregados. A firmar que o sucesso dessa abordagem ultrapassa o mero militantismo, do qual todos sublinham a crise, e caminha para o engajamento no profissionalismo encontra uma oposição real nos sindicatos, tamanho é o temor de ver os assalariados e os sindicalizados desprovidos de seu instrumento histórico. No entanto, essa mudança - não menos histórica - parece-nos, com a organização global do sindicalismo para responder à globalização do capital, a única via para organizar uma resistênda ofensiva à altura das ameaças que vêm surgindo particularmente por meio da lenta oligopolização dos mercados. 0 controle dessa nova máquina sindical não deveria levantar mais problemas do que 0 controle das direções de empresa pelos acionistas. As dificuldades e os riscos de burocratização nos parecem menores do que o perigo que se corre em ver os trabalhadores desprovidos de todo o contrapoder diante da irresistível demanda de taxas de lucro crescentes que a financerização da economia mundial sustenta à sua maneira. 


\section{Estresse e otimismo}

Este artigo mostra a coerência sistêmica da nova combinatória produtiva fundada sobre o fluxo tensionado, o teamwork e o modelo da competência. Pode essa coerência superar as contradições da relação salarial capitalista? O u antes, onde estão as contradições entre capital e trabalho nessa nova combinatória?

De um lado, o modelo é o da saída da crise de acumulação do capital (com os empréstimos ao modelo japonês outrora próspero). Então, ele pode estar ameaçado quando as condições de manutenção da implicação constrangida desaparecerem no 0 cidente, isto é, quando da volta a um quase pleno-emprego, que reduziria consideravelmente a concorrência entre os assalariados. Estes poderiam, assim, voltar a formas de resistência e, por exemplo, simular comportamentos de lealdade para satiffazer a demanda gerencial, adotando no mesmo movimento atitudes contrárias. Conseqüentemente, essa nova combinatória produtiva seria apenas um modelo de transição em direção a algo ainda desconhecido hoje.

D e outro lado, pode-se mostrar que, durante a última crise de acumulação, o capital aprendeu uma nova conduta (nova ao menos em relação aos Trinta G loriosos) ${ }^{15}$, qual seja, a sistematização da precariedade. $\mathrm{O}$ u, dito de outra forma, a invenção da precariedade estrutural por meio da generalização do modelo núcleo/periferia, chegando até o cerne de suas engrenagens (gestão da força de trabalho, gestão do capital, concepção dos produtos, entre outras). D esse ponto de vista, durante a crise, o capital talvez tenha aprendido muito mais do que os trabalhadores, já que o sindicalismo parece ter perdido algumas de suas funções e encontrado dificuldade para descobrir novas. Se para o salariado sempre houve uma troca desigual, a distribuição das capacidades de aprendizagem entre as duas partes também 0 é. M as, o paradoxo do paradoxo é que os trabalhadores aprendem mais durante períodos de crescimento econômico, quando a pressão sobre eles é menor: o período atual abre, portanto, as portas para novas invenções.

\section{Referências Bibliográficas}

Boyer, R . \& D URAN D, J.-P. (1998), L'après fordisme. Paris, Syros.

Dur an D, J.-P. (ed.) (1994), La fin du modèle suédois. Paris, Syros. . (1999a), "Le nouveau modèle productif". In: Bollier , G. \& Dur AN D, C. (orgs.).La nouvelle division du travail, Paris, L'Atelier.

. (1999b), "Syndicalisme et nouveau modèle productif”. L a Pensée, jul.-ago.-set., Paris (2000a), "Les enjeux de la logique compétences: gérer et comprendre". A nnales des
15. Período que compreende, grosso modo, do final da Segunda Guerra $\mathrm{M}$ undial até a primeira crise do petróleo (N . do T.). 
M ines, S.I.

.. (2000b), "Combien y a-t-il de souffrance au travail?". Sociologie du Travail, 3, Paris. . (2001), “O modelo da competência: uma nova roupagem para vel has idéias”. R evista

L atinoamericana de Estudios del Trabajo, S.I., 7 (14).

D u R An D,J.-P.; St EWART, Paul \& C ASt ILLo, J.J. (1998), L'avenir du travail à la chaîne: une comparaison internationale dans I'industrie automobile Paris, La Découverte.

Durand, J.-P. \& Durand-SebaG, J. (1996), T he hidden face of the japanese model. M elbourne, M onash A sia Institute.

Dur and, J.-P. \& H atzfeld, N . (2002), “La chaîne et le réseau: Peugeot-Sochaux, ambiences d'intérieur". C ahiers L ibres, Paris, Editions Page D eux.

O нnо, T., (1989), L'esprit toyota. S.I., M asson.

SH Im IzU, K . (1999), L e toyotisme. Paris, La D écouverte (coleção R epères).

\section{Resumo}

0 artigo propõe o conceito de "fluxo tensionado" como elemento presente em diversas situações de trabalhado na atualidade, configurando uma nova combinatória produtiva. Essas situações não se reduzem ao método do just-in-time de organização, podendo ser capturadas tanto no segmento industrial como nosserviços e nas relações comerciais entre firmas. 0 texto está dividido em cinco partes: na primeira faz-se uma breve introdução sobre o contexto econômico e social em que se insere a utilização do fluxo tensionado; na segunda, ele é definido à luz das inovações recentes na produção e no trabalho (modelo japonêse lean-production); na terceira parte, mostra- se como a discussão contemporânea so bre competências é coerente com o novo formato; na quarta, interroga-se sobre o papel do sindicalismo diante do novo desafio; e, finalmente, na quinta parte, adverte-se para as limitações de sua aplicação em um cenário pró-trabalho.

Palavras-chaves: N ovo modelo produtivo; Pós-fordismo; Toyotismo; Competência.

Jean Pierre Durand é professor de Sociologiae diretor do $C$ entre Pierre $\mathrm{N}$ aville, U niversidade d'Evry (França).

\section{Abstract}

The "flux tendu" concept as an element present in various current work situations, which shape a new productive combination. T hese situations cannot be reduced to the just-in-time method of organization, and can be employed not only in industries but also in services and in the commercial relations between firms. The text is divided into five parts: the first is a short introduction on the economic and social context in which the use of the flux-tendu is inserted; in the second, it is defined in view of the recent innovations in production and in work (the Japanese model and lean-production); in the third part, the contemporary discussion on competencesis shown to be coherent with the new format; in the fourth, the role of the unions facing this new challenge is discussed; and, finally, in the fifth, there is a warning on the limit to its applications in a pro-labor scenario.

Key words: N ew productive model; Post-fordism; Toyotism; Competence. 